\title{
SISTEMA NACIONAL DE EDUCAÇÃO E RELAÇÕES INTERGOVERNAMENTAIS NO BRASIL ${ }^{1}$
}

\author{
Marisa R. T. Duarte * \\ M. Rosimary Soares SANTOs*
}

\begin{abstract}
RESUMO: A hipótese analisada nesse artigo considerou o discurso político sobre a constituição de um Sistema Nacional de Educação no Brasil como expressão de novo arranjo institucional para as relaçôes intergovernamentais no sistema educacional federativo. O objetivo do estudo é compreender que elementos e mecanismos compóem o quadro analítico condutor de políticas públicas em educação para a nação. Para este fim, analisou-se a legislação constitucional de regulação institucional das relaçóes entre os entes federados, a Lei que aprovou o novo Plano Nacional de Educação e o projeto de Lei Complementar, que objetiva regulamentar relaçốes intergovernamentais no Sistema Educacional brasileiro. $\mathrm{O}$ estudo concluiu a respeito do silêncio discursivo em torno de políticas de cunho redistributivo e da regulamentação de relaçóes intergovernamentais mediante normas infra legais.
\end{abstract}

Palavras-chave: Sistema Nacional de Educação. Relaçóes intergovernamentais nos sistemas educacionais. Federalismo e educação.

\section{THE NATIONAL EDUCATION SYSTEM AND INTERGOVERNMENTAL RELATIONS IN BRAZIL}

\begin{abstract}
The hypothesis analyzed in this article considered the political discourse about the establishment of a Brazilian National Education System as an expression of a new institutional arrangement for intergovernmental relations in the federative educational system. The objective of this study was to understand which elements and mechanisms draw up the analytical framework that drives the nation's public policies in education. To this end, the following documents were analyzed: the legislation that affected the institutional regulation of the relations between federated entities; the law that approved the new National Education Plan and the Complementary Law project, which aims to regulate intergovernmental relations regarding the Brazilian Education System. The study concluded that there is a discursive silence around redistributive policies
\end{abstract}

* Universidade Federal de Minas Gerais, Faculdade de Educaçáo, Departamento de Administração Escolar, Belo Horizonte, MG, Brasil. E-mail de contato: mmduarte@ufmg.br

** Universidade Federal de Minas Gerais, Faculdade de Educação, Grupo de Pesquisa Política e Administração de Sistemas Educacionais, Belo Horizonte, MG, Brasil. 
and regulation of intergovernmental relations by means of non-statutory regulations.

Keywords: National Education System. Intergovernmental relations in education systems. Federalism and education.

\title{
SYSTÈME NATIONAL D'ÉDUCATION ET RELATIONS INTERGOUVERNEMENTALES AU BRÉSIL
}

\begin{abstract}
RESUMÉ: L'hypothèse examinée dans cet article a considéré le discours politique sur la création d'un Système National d'Education au Brésil traduit comme un nouvel arrangement institutionnel pour les relations intergouvernementales dans le système éducatif fédéral. L'objectif de cette étude est de comprendre que les mécanismes et les éléments constituent le cadre analytique pilote des politiques publiques en matière d'éducation pour la nation. À cette fin, nous avons analysé la loi constitutionnelle de régulation institutionnelle des relations entre les entités fédérées, la loi qui a approuvé le nouveau Plan National d'Education et le projet de loi complémentaire, qui vise à réglementer les relations intergouvernementales dans le système éducatif brésilien. L'étude a conclu qu' il y a un silence autour de la nature discursive de redistribution des politiques et des réglementations des relations intergouvernementales par des normes infra légales.
\end{abstract}

Mots-clés: Éducation nationale. Relations intergouvernementales dans les systèmes éducatifs. Fédéralisme et éducation.

\section{Contextos e referentes de análise}

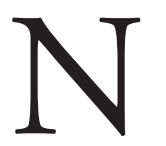

o Brasil persiste uma desconfiança com o arranjo institucional federativo que tem por suporte, por um lado, o sentimento comum de pertencimento a uma comunidade nacional (forjado desde o século XIX), associado à desconfiança da capacidade das elites locais, compreendidas como fontes de corrupção e clientelismo, para implementar os direitos dos cidadãos. Por outro lado, uma tradição política autoritária, que centralizou recursos técnicos e financeiros no executivo federal, resultou em poderes públicos locais com menor capacidade técnica e financeira de intervenção para o atendimento de demandas sociais. Por essas razóes e como sintetiza Arretche (2010), provém maior legitimidade da funçáo legislativa da União, pois embora os governos subnacionais tenham um papel importante no gasto público e na provisão de serviços, suas decisóes são largamente afetadas pela regulação federal.

Nos últimos 15 anos, desde a aprovação da LDBEN, ocorreram mudanças institucionais de cunho incremental no Sistema Educacional Federativo Tripartite Brasileiro. A partir de 2009, a direção proposta para essas mudanças foi 
explicitada com introdução no texto constitucional do objetivo de articulação, pela via do planejamento de um Sistema Nacional de Educação em regime de colaboração. (BRASIL, 1988, art. 214,) Alteraçôes postas no texto constitucional, efetuadas em diferentes governos, por sua natureza incremental são processadas em níveis diversos e tem capacidade de constranger decisóes futuras e/ou limitar a capacidade dos governos subnacionais em adotar novas políticas ou reverter a rota das atuais.

Com suporte em Foucault (2008), consideramos o discurso político como modos de enquadramento entre conhecimentos, valores e práticas, eixo de produção e transmissão de lógicas partilhadas de ação. Os discursos políticos não refletem ou representam práticas políticas e sociais, elas as constroem ou as constituem. (FAIRCLOUGH, 2001) As instituiçóes existem pelo fato de produzirem discursos e "comunidades discursivas", ou seja, produzirem uma ordem política simbólica em torno de processos produtivos e interpretativos de signos orientadores de lógicas partilhadas de ação. A crítica orientadora deste estudo, na contramão dos referentes mais finalísticos de análise das políticas públicas em educação - centrados na investigação e avaliação do atendimento a demandas socioeducacionais produzidas por diferentes atores -, volta-se para a compreensão do modo e de como, construímos, na atualidade, uma racionalidade aglutinadora de ações na formulação de políticas públicas em educação. O que está em análise são as traduçôes do discurso político em torno do SNE na construção de políticas públicas e na implementação de mudanças institucionais.

Recentemente, a tese de doutorado de Dupuy (2012), sobre as políticas regionais para o ensino secundário francês, mediante métodos qualitativos de investigação comparada, nos alertou para a importância do desenvolvimento de ferramentas analíticas, capazes de desvelar mecanismos ${ }^{2}$ produtores de laços de causalidade entre o que se busca explicar e seus elementos explicativos. Destacou Dupuy (2012) a importância da análise de congruências de causalidades complexas, mediante o estudo de casos comparados, e acrescentou à análise descriçóes de como operam "mecanismos específicos", responsáveis por revelar novas proposiçóes analíticas, nos casos onde os pontos de observação, no tempo e/ou no espaço, são relativamente numerosos. Uma segunda linha de análise, proveniente da sociologia política francesa, encontra-se nos estudos de Ben-Ayed (2007; 2009; 2010). Este pesquisador convida para o desenvolvimento teórico e metodológico de investigaçóes capazes de apreensão das relaçóes de interdependência entre a esfera nacional e as locais, contrapondo-se as estratégias epistemológicas que apreendem os locais como figura de singularidades e a esfera nacional como portadora de racionalidade estratégica totalizante. Analisa as mudanças produzidas no sistema educacional francês a partir das lógicas locais de ação e aponta para a reconfiguração da articulação entre Estado e sociedade na França, a partir das arenas e do ponto de vista dos atores locais. 
Esses estudos de Dupuy (2012) e de Ben Ayed (2007; 2009 e 2010) rejeitam a noção de que Sistemas Nacionais de Educação estão convergindo para um único modelo, e apontam para a urgência de ferramentas analíticas potencialmente capazes de capturar as mudanças que estão, indiscutivelmente, acontecendo em diferentes países e suas localidades. Em consequência, advogam por referentes que não subestimem a extensão de mudanças pontuais, ou as codifiquem apenas como pequenos ajustes adaptáveis às circunstâncias alteradas no serviço da reproduçáo contínua dos sistemas existentes.

Neste momento, quando discutimos no Brasil a configuração de um Sistema Nacional de Educação, esse estudo indaga: como operamos mudanças de cunho incremental no sistema educacional federativo e desigual presente neste país? Que mudanças institucionais estão em desenvolvimento e em qual direção, para atribuir significados a ideia de um Sistema Nacional de Educação no Brasil, sob as bases de uma desigual organização política federativa?

Para esses fins, o artigo foi subdivido em três partes. No primeiro momento expomos os elementos e dispositivos da formação discursiva, mais contemporânea, em torno da configuração de um Sistema Nacional de Educação em um país de organização federativa. Em seguida, descrevemos as medidas provocadoras de mudanças institucionais no sistema educacional federativo brasileiro e suas possíveis repercussóes. Por último, analisamos dois tópicos referentes às novas relaçóes intergovernamentais em curso: as funçóes da União e a atuação dos entes subnacionais. Em síntese, pressupomos que o estudo das relaçóes intergovernamentais é uma vertente analítica importante, para a compreensão do modus operandi das mudanças em curso no sistema educacional no Brasil.

\section{Sistema Nacional de Educação, federação e planejamento normativo}

Em 1932, O Manifesto dos Pioneiros da Educação Nova (BRASIL, 1932) - documento programático que sistematizou proposições de intelectuais brasileiros com posições diversas no espectro político de então - continha um diagnóstico da inexistência de um Sistema Nacional de Educação no país. No documento de 1932, a ideia de planejamento normativo no âmbito educacional recebeu suas primeiras traduçóes. (HORTA, 1982; SAVIANI, 1999) Azanha (1993) esclarece que naquele período tratava-se da defesa de uma atuação mais racional e sistêmica dos poderes públicos. O Manifesto dos Pioneiros continha uma denúncia à formulação de políticas para área educacional da época e uma exigência de planejamento cientifico, que livrasse a ação educativa do empirismo e da descontinuidade dos políticos. Como nos alertou Saviani (1999) o "plano" era entendido como um 
instrumento de introdução da racionalidade científica no campo da educação em consonância com o ideário escolanovista para o qual:

[...] os trabalhos científicos no ramo da educação já nos faziam sentir, em toda a sua força reconstrutora, o axioma de que se pode ser tão científico no estudo e na resolução dos problemas educativos, como nos da engenharia e das finanças. (BRASIL, 1932)

Foi a aprovação da Lei de Diretrizes e Bases n. 4.024 de 1961 (BRASIL, 1961) que explicitou as linhas gerais do arranjo institucional federativo para o sistema educacional brasileiro, ao estabelecer especificamente a formulação de diretrizes e bases e planos nacionais como competência da União, bem como a regulação de controle da educação superior. Aos estados subnacionais e municípios competiria a efetivação do direito à educação no âmbito do entâo ensino primário e médio. (CURY, 2008; 2010) É esta soluçáo institucional que receberá críticas e novas formulaçóes, desde o processo constituinte à aprovaçáo da Lei de Diretrizes e Bases de 1996. (BRASIL, 1996a)

Em novembro de 1988 foi apresentado à Câmara dos Deputados o projeto de Lei n. 1.258 (BRASIL, 1988a), que fixava as diretrizes e bases da educação nacional. Projeto de Lei de iniciativa do legislativo, esta proposição estabelecia a criação de um Sistema Nacional de Educação responsável por articular de modo coerente as diferentes redes de ensino, estabelecia o regime de colaboração entre os entes federados como modo de organização da educaçáo pública e lhes atribuía competências diferenciadas para o desenvolvimento dos diferentes tipos de educação escolar, como também para autorização de funcionamento e supervisão dos estabelecimentos de ensino. A partir de 1989 teve início um processo inédito de consulta, debates e mobilização da sociedade em torno da redação do texto de diretrizes e bases da educação (SAVIANI, 1997), o que resultou, em 1990, na proposição conhecida como "2o Substitutivo Jorge Hage". Ao analisar esta proposição Saviani (1997) afirma que, não obstante os avanços em torno do conceito de SNE, a questáo permanecia ainda nebulosa, entretanto a redação substitutiva, apresentada pelo Deputado Jorge Hage em 1990, continha dispositivos que explicitavam novos arranjos institucionais na composição e organização do Sistema Nacional de Educação.

$\mathrm{Na}$ tramitação da primeira proposição legislativa sobre diretrizes e bases da educação, após a Constituição de 1988, diferentes atores sociais empenharam-se na construção de um texto que buscava explicitar os arranjos promotores da intervenção do Estado na garantia do direito social à educaçáo, ou seja, explicitar medidas orientadoras do dever do Estado para com a educaçáo, mencionado no texto constitucional. (BRASIL, 1988, caput, art. 205,) Sob a noção de Sistema 
Nacional de Educação, a emergência de mudanças institucionais nas relaçóes intergovernamentais no campo educacional explicitadas no início da década de 1990, é parte inseparável da construção de um sistema de proteção social voltado para a incorporação do conjunto da populaçâo em bases mais igualitárias e universalistas. No entanto, e sob a influência dos princípios político e administrativos conhecidos como new public management, o que ocorreu foi a aprovação da Lei de Diretrizes e Bases da Educação Nacional (LDBEN) no 9. 394 (BRASIL, 1996a), hoje vigente, e que suprimiu o título relativo ao SNE.

\section{Tabela 1}

Dispositivos orientadores de arranjos institucionais do Sistema Nacional de Educação, previstos no substitutivo Jorge Hage, 1990

\begin{tabular}{|c|c|c|}
\hline \multirow{2}{*}{$\begin{array}{l}\text { Dispositivo } \\
\text { Art. } 10\end{array}$} & \multicolumn{2}{|c|}{ Conteúdo } \\
\hline & $\begin{array}{l}\text { Competência normativa e } \\
\text { de coordenação ao } \mathrm{CNE}\end{array}$ & $\begin{array}{l}\text { Competência executiva ao } \\
\text { Ministério de Educação }\end{array}$ \\
\hline $\begin{array}{l}\S \text { único, art. } \\
10 \text { e art. } 25 .\end{array}$ & $\begin{array}{l}\text { Fórum Nacional de } \\
\text { Educação, estaduais, } \\
\text { regionais e municipais }\end{array}$ & $\begin{array}{l}\text { Como instância de } \\
\text { consulta e articulação } \\
\text { com a sociedade }\end{array}$ \\
\hline $\begin{array}{l}\text { Art. } 11,12,13 \\
\text { e } 14\end{array}$ & \multirow{2}{*}{\multicolumn{2}{|c|}{$\begin{array}{l}\text { Composição e atribuição dos sistemas de ensino por } \\
\text { ente federado } \\
\text { Função redistributiva da União para com os demais } \\
\text { entes federados }\end{array}$}} \\
\hline$\S 2^{\circ}$, Art. 12 & & \\
\hline Art. 15 & \multicolumn{2}{|c|}{$\begin{array}{l}\text { Princípio de gestão democrática mediante a forma } \\
\text { colegiada e representativa, com participação de }\end{array}$} \\
\hline$\S 2^{\circ}$, Art. 17 & \multicolumn{2}{|c|}{$\begin{array}{l}\text { O dever e o conteúdo da colaboração entre os entes } \\
\text { federados }\end{array}$} \\
\hline Art. 114 & \multicolumn{2}{|c|}{$\begin{array}{l}\text { Plano Nacional de Educação, quinquenal, aprovado } \\
\text { em Lei, com o objetivo de articular as relações }\end{array}$} \\
\hline
\end{tabular}

Fonte: Saviani, 1997, p. 74-82.

Passados quase 80 anos da divulgação do Manifesto e 18 anos da aprovação da LDBEN, assistimos, em 2009, a introdução de emenda ao texto constitucional (BRASIL, 2009), que atribuiu ao Plano Nacional de Educação o objetivo de articular o Sistema Nacional de Educação. A redação constitucional de 2009 compele ao PNE funçóes de reforma sistêmica, ou seja, de definir diretrizes, objetivos, metas e estratégias de implementação, de assegurar a manutenção e desenvolvimento do ensino por meio de açóes integradas dos poderes públicos das diferentes esferas federativas (BRASIL, 1988, art. 214). Esta mesma Emenda Constitucional (BRASIL, 2009) ampliou, também, a faixa etária de frequência obrigatória e oferta gratuita, de modo a determinar a ação responsável do Estado e 
suas obrigaçóes correspondentes para a população na faixa etária de 4 a 17 anos e para jovens e adultos que dela náo tiveram acesso na idade própria.

Com a redação constitucional aprovada a partir de 2009 (BRASIL, 1988, art. 214), a existência de um Sistema Nacional de Educação passou a ser considerada como ex ante, ou seja, algo projetado e prognosticado para o país. Em consequência o desafio político-administrativo de planejamento encontrar-se-ia na seleçáo de medidas para cumprimento dos objetivos gerais previstos nos incisos subsequentes, que estabelecem metas a serem atingidas. (BRASIL, 1988, art. 214) Desse modo, o texto constitucional estabeleceu o planejamento normativo como o meio de articulação do Sistema Nacional de Educação ${ }^{3}$ e as metas e estratégias nele contidas, meios de promover açóes integradas dos poderes públicos das diferentes esferas federativas.

Um plano de reconstrução integral, comum a todos os entes federados, preconizado em 1932, é estabelecido e delineado no texto constitucional a partir de 2009 e o planejamento normativo torna-se o instrumento de articulação dos entes federados. Permanece como elemento discursivo aglutinador de práticas e direcionador das mudanças pretendidas o diagnóstico formulado em 1932, da ausência de um Sistema Nacional de Educação no país, devido a suas desigualdades e a ideia do plano como instrumento de racionalidade orientadora das açóes em contraposição a interesses políticos. No entanto, como a organização federativa é clausula pétrea da Constituição ( $\$ 4^{\circ}$, art. 60, Brasil, 1988), os termos utilizados nos documentos legais e governamentais passaram a enfatiza a ideia de organização do Sistema Nacional de Educação articulado e/ou de regime de colaboração entre os entes federados, que emergiu com as proposiçóes de Lei de Diretrizes e Bases após 1988.

Expressóes semelhantes encontram-se nos documentos orientadores da Conferência Nacional de Educação, realizada em 2010. Entidades educacionais diversas, organizadas pela Campanha Nacional pelo Direito à Educação, reiteram esses princípios de regulação do discurso político sobre o SNE. Por sua vez, a Conferência Nacional (CONAE 2014), realizada de 18 a 21 de novembro de 2014, reuniu como princípios orientadores: a participação popular, a cooperação federativa e o regime de colaboração na articulação do SNE. Esses termos nuançam as mudanças pretendidas nas relações intergovernamentais no campo educacional e influenciam os arranjos institucionais pretendidas.

\section{Discursos configuradores do Sistema Nacional de Educação}

Em 2007 o executivo federal divulgou para o país o chamado Plano de Desenvolvimento da Educação (PDE), documento que reunia um conjunto de açóes 
e programas do Ministério da Educação, além de orientar quanto a princípios, objetivos e procedimentos reguladores das relações intergovernamentais. É extensa a literatura de análise sobre o contexto de formulação, conteúdo e possíveis efeitos do PDE (ADRIÃO; GARCIA, 2008; CAMARGO et al., 2008; KRAWCZYK, 2008; ABREU, 2010; MASSON, 2012; DUARTE; JUNQUEIRA, 2013). Em relação a este estudo, destacamos que a divulgação do PDE condicionou o apoio técnico e financeiro do Ministério da Educação à assinatura, pelos estados, Distrito Federal e municípios, do plano de metas Compromisso Todos pela Educação. Depois da adesáo ao Compromisso, os entes federativos devem elaborar o Plano de Açóes Articuladas (PAR) para habilitarem-se a receber assistência financeira da União, sem assinatura de acordo ou convênio. (FNDE, 2014)

No ano seguinte, em 2008, proveniente da Câmara dos Deputados, é apresentada ao Senado a PEC n. 277/2008, que provocou a EC n. 59/2009. (BRASIL, 2009) Esta PEC propunha originalmente a redução anual, a partir do exercício de 2009, do percentual da Desvinculação de Receitas da União (DRU) incidente sobre os recursos destinados à manutenção e desenvolvimento do ensino. No âmbito do Congresso Nacional tinha-se a apresentação, nesse mesmo período, de diversas proposições para a ampliação dos percentuais vinculados à MDE: PECs n. 416 de 2001; n. 538 e 577 de 2006 e n. 47 de 2007, dentre outras. Essas propostas legislativas sinalizavam para a necessidade de ampliação dos recursos tributários vinculados à manutenção e desenvolvimento do ensino, em especial os da Uniāo. Em direção semelhante, entidades e movimentos organizados ${ }^{4}$, muitos deles com vínculos com o Partido dos Trabalhadores, acrescentavam reivindicações de ampliaçấo dos recursos financeiros destinados à MDE com fundamentos diversos como: o conceito de um "custo aluno qualidade", a defesa de um piso salarial profissional, a insuficiência dos recursos municipais, etc.

Em 2009, já no contexto de preparação da Conferência Nacional de Educação de 2010, o dispositivo original, que provocou a EC no 59 de 2009 recebeu substitutivo que aglutinava outros temas. Dentre esses, as alteraçóes sobre o planejamento educacional (BRASIL, 1988, art. 214) e a colaboração da Uniấo para a universalização do ensino obrigatório. (BRASIL, 1988, art. 211, $\left.\mathbb{S} 4^{\circ}\right)^{5} \mathrm{~A}$ alteração constitucional que projeta um Sistema Nacional de Educação para o país emerge das discussóes relacionadas à ampliação dos recursos provenientes da União para a educação e, nos dois anos seguintes, se sobrepóe o tema do percentual de recursos do Produto Interno Bruto a ser vinculado normativamente. Foi neste contexto que o executivo federal demonstrou novo protagonismo, conforme afirma Oliveira (2011) ao analisar as ações do Ministério da Educação, a partir do segundo mandato de Luís Inácio Lula da Silva. [N.E.: 35․ Presidente da República Federativa do Brasil, período de 01.01.2003 a 01.01.2011].

A partir de 2007, um conjunto de medidas veio a público sob a égide do MEC e procurou dar direção à política educacional no país. Este estudo argu- 
menta, a partir da sugestâo apresentada por Oliveira (2011), que a base para uma orientação comum, apesar dos aberrantes desequilíbrios [federativos], envolveu a disseminação do discurso sobre a configuração do Sistema Nacional de Educação. Para Chabrol (1990) a construção de um princípio regulador sociocognitivo-linguageiro, age durante o desenvolvimento do discurso para controlar a "boa" construçáo discursiva com vistas a finalidades identitárias. Com fundamento em Charaudeau (2012) afirmamos, assim, que o princípio de regulação disseminado ao evocar-se a construção de um SNE, permite dominar e coordenar o jogo das influências contraditórias presentes no sistema educacional, e ao sujeito comunicante (in casu o MEC) por em movimento praticas discursivas de modo coordenado para atingir objetivos políticos.

Quais objetivos são esses? Uma primeira hipótese para análise dos estudos comparados em gestão municipal da educaçáo envolve a estrutura regulatória dos recursos vinculados a MDE. A importância atribuída à regulamentação do SNE no último decêndio tem por fundamento legitimador a superação de desigualdades socioeducacionais, causa e consequência de um sistema educacional de matriz federativa. Parecer orientador das discussóes no âmbito do Conselho Nacional de Educação (SAUER, 2012) afirma que uma das medidas iniciais de organizaçáo do regime de colaboraçáo entre os entes federados encontrou-se na aprovação dos mecanismos compulsórios de colaboração na área de financiamento: Fundo de Desenvolvimento do Ensino Fundamental (Fundef) (BRASIL, 1996) e, posteriormente, da Educação Básica (Fundeb). (BRASIL, 2006) Ao redistribuir recursos, já vinculados à manutenção e desenvolvimento do ensino, a desigualdade de financiamento regional e estadual no país, mais evidenciada, impulsionou demandas por maior participação financeira da União.

\section{Relações intergovernamentais: revendo as funções da União}

A análise de conteúdo do documento final da Conferência Nacional de Educação ${ }^{6}$ nos permitiu identificar, como um dos elementos centrais de construção da formação discursiva em torno do Sistema Nacional de Educação, a regulamentação da um regime de colaboração de matriz redistributivo:

A regulamentação do Regime de Colaboração deve explicitar a participaçáo da União na cooperaçáo técnica e, especialmente, na determinação de transferências regulares e continuas de recursos financeiros às instituiçoos públicas dos Estados, DF e Municípios, priorizando os entes federados com baixos indices de desenvolvimento socioeconômico e educacional, tendo como critérios indicadores o IDH, altas taxas de pobreza, índice de fragilidade educacional na oferta de EJA, dentre outros, que permitam indicar aqueles 
que mais demandam apoio para a garantia do custo aluno(a)-qualidade (CAQ). Esta regulamentaçáo deve, ainda, prever meios de superação das desigualdades regionais, especialmente por meio da construção de uma política de financiamento, ancorada na perspectiva do CAQ. (BRASIL-CONAE, 2010, p. 25) [grifo dos autores].

O documento final da Conferência Nacional de 2010 (BRASIL/CONAE, 2010) orientava para a regulamentação das transferências (constitucionais obrigatórias e voluntárias) dos recursos, especialmente os provenientes da União, devido à reduzida participação do poder central no financiamento da educação básica. Esta orientação recebeu tradução expressiva no texto da Lei no 13.005 de 2014 (BRASIL, 2014), que instituiu o Plano Nacional de Educação com a explicitação de 17 programas estratégicos para a atuação da União (Tabela 2). Cabe ressaltar que esses programas têm por suporte um mecanismo de monitoramento das relaçóes intergovernamentais, no âmbito da educação básica, denominado Plano de Açôes Articuladas, disseminado a partir de 2007. (ADRIÃO; GARCIA, 2008; DUARTE; JUNQUEIRA, 2013)

O texto da Lei que instituiu o PNE adotou, simultaneamente, as denominaçóes "programa nacional" e "programas" ao longo de 17 açôes estratégicas previstas em suas metas (Tabela 2). Se o texto constitucional reformulado em 2009 atribuiu ao PNE a articulação, em regime de colaboração, dos entes federados, esse princípio de configuração do SNE recebeu no PNE 2014-2024 (BRASIL, 2014) uma tradução, que deslizava para a competência da Uniấo na formulação e financiamento de programas nacionais na área de educação a serem implementados localmente. Desse modo, a Lei do PNE (BRASIL, 2014) referendou a regulamentaçáo das relaçóes intergovernamentais, já estabelecida em 2012, conhecida como Lei do PAR, para a assistência técnica e financeira, prestada em caráter voluntário pela União aos estados e munícipios. (BRASIL, 2012)

Entretanto, se esses são programas de abrangência nacional, todos apresentariam forte característica distributiva. Ou seja, a decisão de onde aplicar os recursos, sejam técnicos ou financeiros, é efetuada no âmbito do executivo federal. São conhecidos como transferências voluntárias de recursos, sem qualquer obrigatoriedade legal definida a respeito do valor da quantia transferida ou qualquer indicação do ente federado que será beneficiado pelo recurso. As disposiçôes constantes no documento final da Conae (BRASIL/CONAE, 2010), que apontavam para transferências regulares e contínuas de modo a concretizar a ideia de Sistema Nacional de Educação, foram atendidas. Entretanto, a função redistributiva da União, já prevista no texto constitucional (BRASIL, 1988, art. 212, $\$ 1^{\circ}$ ) e propugnada no documento final da CONAE 2010 permaneceu esquecida. 


\section{Tabela 2}

Programas estratégicos para a atuação da União, constantes no PNE 2014-2024

\begin{tabular}{|c|c|c|c|}
\hline & Programas estratégicos & Localização no texto & $\begin{array}{c}\text { Classificação da função } \\
\text { esperada }\end{array}$ \\
\hline 1 & $\begin{array}{l}\text { Programa de nacional de construção e reestruturação } \\
\text { de escolas, bem como de aquisição de equipamentos; } \\
\text { [programa nacional de reestruturação e aquisição de } \\
\text { equipamentos para escolas públicas; instituir, em } \\
\text { regime de colaboração, programa [nacional?!] de } \\
\text { construção de escolas; programa nacional de } \\
\text { ampliação e reestruturação das escolas públicas] }\end{array}$ & $\begin{array}{l}\text { Meta } 1 \text { - estratégia } 1,5 ; \text { Meta } \\
\text { 6- estratégia } 3,2 ; \text { Meta } 7 \\
\text { estratégia } 7.19 ; \text { Meta } 10 \\
\quad \text { estratégia } 10.5\end{array}$ & $\begin{array}{l}\text { Assistência técnica e } \\
\text { financeira }\end{array}$ \\
\hline 2 & Programa nacional de renovação do ensino médio & Meta 3; estratégia 3.1 & Assistência técnica \\
\hline 3 & $\begin{array}{l}\text { Promover, com o apoio da União, a oferta de } \\
\text { educação básica pública em tempo integral }\end{array}$ & $\begin{array}{c}\text { Meta 6; estratégias 6.1, 6.2 e } \\
6.3\end{array}$ & $\begin{array}{l}\text { Assistência técnica e } \\
\text { financeira }\end{array}$ \\
\hline 4 & $\begin{array}{l}\text { Programas [nacionais?!] suplementares de material } \\
\text { didático-escolar, transporte, alimentação e } \\
\text { assistência à saúde }\end{array}$ & $\begin{array}{c}\text { Meta 7, estratégia } 7.17 ; \text { Meta } \\
\text { 9; estratégia } 9.7\end{array}$ & $\begin{array}{l}\text { Assistência técnica e } \\
\text { financeira }\end{array}$ \\
\hline 5 & $\begin{array}{l}\text { Programa nacional de formação inicial e continuada } \\
\text { para o pessoal técnico das Secretarias de Educação }\end{array}$ & Meta 7, estratégia 7.22 & $\begin{array}{l}\text { Assistência técnica e } \\
\text { financeira }\end{array}$ \\
\hline 6 & $\begin{array}{l}\text { Programa [nacional?!] para a formação inicial e } \\
\text { continuada dos profissionais da educação }\end{array}$ & Meta 7; estratégia 7.26 & $\begin{array}{l}\text { Assistência técnica e } \\
\text { financeira }\end{array}$ \\
\hline 7 & $\begin{array}{l}\text { Programa nacional de formação de professores e } \\
\text { professoras e de alunos e alunas para promover e } \\
\text { consolidar política de preservação da memória } \\
\text { nacional }\end{array}$ & Meta 7; estratégia 7.34 & $\begin{array}{l}\text { Assistência técnica e } \\
\text { financeira }\end{array}$ \\
\hline 8 & $\begin{array}{l}\text { Institucionalizar programas e desenvolver } \\
\text { tecnologias [nacionais?!] para correção de fluxo }\end{array}$ & Meta 8, estratégia 8.1 & Assistência técnica \\
\hline 9 & $\begin{array}{l}\text { Implementar programas de educação de jovens e } \\
\text { adultos }\end{array}$ & Meta 8; estratégia 8.2 & $\begin{array}{l}\text { Assistência técnica e } \\
\text { financeira }\end{array}$ \\
\hline 10 & $\begin{array}{l}\text { Criar beneficio adicional no programa nacional de } \\
\text { transferência de renda para jovens e adultos que } \\
\text { frequentarem cursos de alfabetização }\end{array}$ & Meta 9, estratégia 9.4 & Assistência financeira \\
\hline 11 & $\begin{array}{l}\text { Implementar programas de capacitação tecnológica } \\
\text { da população jovem e adulta }\end{array}$ & Meta 9; estratégia 9.11 & Assistência técnica \\
\hline 12 & $\begin{array}{l}\text { Programa nacional de educação de jovens e adultos } \\
\text { voltado à conclusão do ensino fundamental e à } \\
\text { formação profissional inicial }\end{array}$ & Meta 10; estratégia 10.1 & Assistência técnica \\
\hline 13 & Programa nacional de assistência ao estudante & $\begin{array}{l}\text { Meta 10, estratégia } 10.9 ; \\
\text { Meta } 11 \text {; estratégia } 11.12\end{array}$ & Assistência financeira \\
\hline 14 & $\begin{array}{l}\text { Programas de reconhecimento de saberes para fins } \\
\text { de certificação profissional em nível técnico }\end{array}$ & Meta 11, estratégia 11.5 & $\begin{array}{l}\text { Regulamentação e assistência } \\
\text { técnica }\end{array}$ \\
\hline 15 & $\begin{array}{l}\text { Programa nacional de disponibilização de recursos } \\
\text { para acesso a bens culturais pelo magistério público }\end{array}$ & Meta 16 , estratégia 16.6 & Assistência financeira \\
\hline 16 & $\begin{array}{l}\text { Programas de apoio à formação de conselheiros(as) } \\
\text { [locais] }\end{array}$ & Meta 19, estratégia 19.2 & Assistência técnica \\
\hline 17 & $\begin{array}{l}\text { Programas de formação de diretores e gestores } \\
\text { escolares }\end{array}$ & Meta 19, estratégia 19.8 & Assistência técnica \\
\hline
\end{tabular}

Fonte: Brasil, 2014. 
Nesse sentido, importa à pesquisa comparativa analisar projetos e programas sob o referente de sua capacidade maior ou menor de promover a redução de desigualdades. Ou seja, os estudos comparados de âmbito infranacional devem normativamente orientar-se para a busca do modo como as interaçóes entre os entes federados contribuem para redução de desigualdades. Essa redação, mais genérica da Lei de planejamento, subtende que o regime de colaboração, previsto como meio de articulação do SNE, não prescindiria de programas elaborados localmente para finalidades comuns, nos termos postos na norma a participação dos demais entes federados. Entretanto, quais arranjos institucionais acham-se em construção para promover o regime de colaboração, articulador do SNE?

\section{Relações intergovernamentais, planejamento e participação}

No âmbito do poder legislativo acha-se, atualmente, em formulação o projeto de Lei Complementar n. 413 (BRASIL, 2014a) com o objetivo de regulamentar o regime de colaboração entre os entes federados. Esta proposição legislativa contém, dentre outros, dispositivos normativos orientadores da gestão democrática do ensino público e da distribuição intergovernamental de recursos vinculados à manutenção e ao desenvolvimento do ensino. Os elementos do discurso político, que orientam essa nova proposta, foram nucleados em dois tipos, por serem elementos recorrentes do discurso político em torno do SNE: vocalização permanente de novos atores (Tabela 3) como expressão da participação da sociedade, e prescrição das relaçóes intergovernamentais no campo educacional, como expressão da cooperação federativa, ou seja, regulamentação das relaçóes intergovernamentais.

\section{Vocalização permanente de novos atores}

A proposição legislativa ora em formulação (BRASIL, 2014a) recompóe o Sistema Educacional ao normatizar competências e atribuiçóes de antigos e propor novos órgãos colegiados de gestão educacional. Conselhos, Conferências e Fóruns no âmbito dos três entes federados seriam instituídos e/ou regulamentados e para seu funcionamento passariam a receber recursos públicos. $\mathrm{O}$ tema da participação, ou como exposto no texto constitucional, da gestão democrática do ensino público, recebe uma regulamentação na proposta de Lei complementar. (Tabela 3)

A nova proposição legislativa sugere a instituição de Conselhos e Fóruns permanentes - colaboradores na gestão educacional - em todos os entes federados e a serem constituídos na forma estabelecida nos respectivos regulamentos. Após 
a Constituição de 1988, a composição da representação nesses órgãos de gestão colegiada tem sido formada por setores sociais e/ou por entidades que congregam profissionais/trabalhadores da educação. (DRAIBE, 1998; ROJAS BUVINICH, 2014) Importa, também, salientar que essas proposiçóes ocorrem em um contexto de enfraquecimento da representação parlamentar tanto no Brasil, quanto em outros países (AVRITZER, 2007), pois é à forma eleitoral a que se atribui a crise da representação política atualmente, considerada pouco eficaz para expressão da diversidade presente na sociedade.

\section{Tabela 3}

Órgãos/entidades de composição do Sistema Nacional de Educaçâo, constante no Projeto de Lei Complementar n. 413/2014

\begin{tabular}{|c|c|c|c|}
\hline \multicolumn{2}{|c|}{ Órgão/entidade } & Função & $\begin{array}{l}\text { Identificação } \\
\text { do dispositivo }\end{array}$ \\
\hline \multicolumn{2}{|c|}{ Ministério da Educação } & Coordenação & Art. $6^{\circ}$ \\
\hline \multirow[b]{2}{*}{ Conselho } & Nacional & $\begin{array}{c}\text { Formulação e } \\
\text { normativa }\end{array}$ & Art. $7^{\circ}$ \\
\hline & $\begin{array}{c}\text { Federal } \\
\text { Estadual } \\
\text { Municipal }\end{array}$ & Normativa & $\S 1^{\circ}$ e $2^{\circ}$, Art. $7^{\circ}$ \\
\hline \multicolumn{2}{|c|}{ Fórum dos Conselhos } & $\begin{array}{c}\text { Consulta e } \\
\text { coordenação } \\
\text { normativa }\end{array}$ & $\S$ único, Art. $8^{\circ}$ \\
\hline Fórum & $\begin{array}{l}\text { Nacional de } \\
\text { Educação } \\
\text { Estadual de } \\
\text { Educação } \\
\text { Municipal da } \\
\text { Educação }\end{array}$ & $\begin{array}{l}\text { Consulta, } \\
\text { mobilização e } \\
\text { articulação }\end{array}$ & Art. $9^{\circ}$ \\
\hline \multirow{2}{*}{ Conferências } & $\begin{array}{c}\text { Nacionais de } \\
\text { Educação }\end{array}$ & $\begin{array}{c}\text { Fornecer } \\
\text { subsídios e } \\
\text { avaliação do } \\
\text { PNE }\end{array}$ & $\S 2^{\circ}$ e $3^{\circ}$, art. 10 \\
\hline & $\begin{array}{l}\text { Estaduais de } \\
\text { Educação } \\
\text { Municipais de } \\
\text { Educação }\end{array}$ & $\begin{array}{l}\text { Fornecer } \\
\text { insumos para } \\
\text { avaliação }\end{array}$ & $\S 4^{\circ}$, art. 10 . \\
\hline \multicolumn{2}{|c|}{$\begin{array}{c}\text { Mesa nacional permanente de } \\
\text { valorização dos profissionais da } \\
\text { educação }\end{array}$} & Sem atribuição & Inc. VIII, art. 15 \\
\hline \multicolumn{2}{|c|}{$\begin{array}{c}\text { Comissão Tripartite Permanente } \\
\text { de Pactuação Federativa }\end{array}$} & $\begin{array}{l}\text { Deliberativa, de } \\
\text { regulação, } \\
\text { operacional e } \\
\text { normativa }\end{array}$ & Art. 14 e 15 \\
\hline
\end{tabular}

Fonte: Brasil, 2014. 
Outro aspecto para o qual chamamos atenção é a absoluta lacuna ao longo dos debates em torno do SNE e de suas instâncias de participação sobre os processos de escolha dos representantes. A escolha das organizaçôes e/ou dos atores sociais, que representarão a chamada, por oposição ao aparato estatal, "sociedade civil” nas entidades/órgáos que compóem o SNE não é universalista. Os eleitos e os eleitores acham-se vinculados a trajetórias políticas dessas entidades e/ ou a vontade do gestor ou, a influência de partidos políticos e grupos sociais mais organizados. Entretanto, o elemento construtor do discurso orientador dessas proposiçóes relaciona-se à participação, como sinônimo de gestão democrática. Este é um tema recorrente na literatura de política educacional brasileira. (FERREIRA, 2004; SOUZA, 2009; SOUZA; CASTRO, 2012) E a literatura em sociologia política analisa o modo como esses órgãos de gestão colegiada contribuem para a formulação de políticas públicas como expressão da articulação entre regulação social e política. (LASCOUMES; LE GALĖS, 2007) Callon et al. (2009) apontam, ainda, suas potencialidades para a "democratização da democracia", como também as ameaças aí contidas. De modo sintético, diríamos que o discurso encobre, por diversas vezes, a complexidade dos fenômenos reais e cabe à análise apreender o modo como o discurso da participação opera no sentido da regulação de controle ou traz às instituiçóes novos dispositivos e disposiçôes de regulação autônoma. A este respeito informam Duarte e Santos (2014): "A produção do consentimento ativo requer práticas discursivas formadoras de valores e objetivos partilhados, orientadores das condutas, e especialmente requer a formaçáo de subjetividades que compartilhem princípios identitários comuns.”

Se examinarmos as competências privativas, passíveis de serem atribuídas a esses órgãos, reiteramos como alerta a conclusão já apresentada por Duarte e Oliveira (2012) para os Conselhos Municipais de Educação, que atuam, na maioria dos casos, sem competências previstas em Lei como entidades de ação complementar aos executivos locais.

\section{Prescrição infralegal de atribuições}

Um segundo tipo refere-se à regulamentação das atribuições dos entes federados em matéria educacional, tema este que compóe o discurso político sobre a organização do Sistema Nacional de Educação, desde os debates em torno da Lei de Diretrizes e Bases da Educação Nacional, após a aprovação da Constituição de 1988, que instituiu o federalismo tripartite. Cury (2002) já advogava pela regulamentação do regime de colaboração entre os entes federados, conforme previsto no texto constitucional. Trata-se, segundo Cury (2009):

[...] de matéria da mais alta importância e significado para o conjunto das açóes públicas e, em especial, para a manutenção 
e desenvolvimento do ensino. A feitura desta lei complementar possibilitaria o aprimoramento na sistematização das competências a fim de coordená-las de modo claro na forma, cooperativo na articulaçáo e eficaz no desenvolvimento e bem-estar dos cidadãos brasileiros.

A defesa da regulamentação do regime de colaboração encontra-se, ainda, em estudos como Saviani (1999; 2008), Araujo (2010); Dourado (2010; 2013) que, ao postularem por um Sistema Nacional de Educação, defendem a importância da regulamentação de relações entre os entes federados vis a vis a construção de formas participativas de novas relaçóes intergovernamentais. Com outras palavras, diríamos que, apesar das diferentes tonalidades postas para aspectos da construção do Sistema Nacional de Educação, estes atores, influentes na elaboração do quadro cognitivo pelo qual apreendemos esse arranjo institucional, argumentam pelo desenvolvimento de um modelo de Sistema Nacional que combine uma regulação burocrática e uma regulação conjunta "Estado-profissionais" de educação. A respeito desse arranjo institucional Maroy (2006) esclarece que ele pode ser organizado de modo mais ou menos descentralizado, mas ele fundamenta-se em normas padronizadas e semelhantes para todos os componentes do sistema.

Qual o desenho proposto no projeto de Lei complementar n 413 (BRASIL, 2014a) para regulamentar relaçóes entre os entes no sistema educacional e, simultaneamente organizar relaçóes intergovernamentais? A proposta legislativa introduz para o sistema educacional, as chamadas Normas Operacionais Básicas (NOB) e atribui a competência de aprova-las à chamada Comissão Tripartite Permanente de Pactuação Federativa. As primeiras NOBs reguladoras de políticas sociais foram elaboradas na década de 1990, no âmbito de um Sistema Único de Saúde, composto constitucionalmente por redes regionais e de modo hierarquizado (art. 196, Brasil, 1988), com o objetivo de disciplinar as atribuiçôes dos entes na prestação dos serviços de saúde. Em artigo onde associam federalismos, desigualdades sociais e a prestação desses serviços, Viana et al. (2002) argumentam quanto a importância das funçóes de regulação sistêmica exercidas pelo governo central, mediante as Normas Operacionais no processo gradativo de descentralização da gestão do SUS. Por sua vez, Arretche (2010) apresenta evidências que Estados federativos, que concentram autoridade regulatória na União, criam mecanismos institucionais que operam na direção da redução das desigualdades. Conclui a autora:

No arranjo [institucional] atual, as transferências constitucionais adotadas em 1988, foram combinadas à limitação da autoridade dos governos locais, a partir de meados dos anos 1990, de modo a garantir que as receitas locais sejam efetivamente destinadas a realizar objetivos políticos estabelecidos pelas arenas decisórias federais. 
Dois aspectos coincidentes nas três proposições de regulamentação dos Sistemas Nacionais de prestação de serviços, que asseguram direitos sociais ${ }^{7}$, são destacados por este estudo: a regulamentação infralegal das relaçóes intergovernamentais e o papel das Comissóes Intergovernamentais, compostas por representantes dos governos subnacionais. Viana et al. (2002) consideram que a atual dinâmica institucional da intervenção pública é caracterizada por grande flexibilidade. Para esses autores, uma flexibilidade institucional implicaria na busca da cooperação intergovernamental para alcançar fins comuns e, para tanto, formar-se-ia esse modelo institucional flexível a partir de medidas legislativas e reguladoras em todos os níveis de governo. No entanto, a elaboração de Normas Operacionais Básicas, em matéria educacional permitirá deslocar a implementação de projetos e programas nacionais para o âmbito local e, simultaneamente, nos termos estabelecidos por Bowe et al. (1992), a construção de projetos, programas e políticas simultaneamente writerly e readerly. Para um Sistema Nacional de Educação as NOBs, como desenhadas na proposta legislativa em análise, acompanhadas pelos Sistemas de Monitoramento e Avaliação coordenados pelo Ministério da Educação, cumpririam função semelhante às previstas para os demais Sistemas de prestação de serviços que asseguram direitos sociais:

O Sistema Nacional de Cultura, organizado em regime de colaboração, de forma descentralizada e participativa, institui um processo de gestão e promoção conjunta de políticas públicas de cultura, democráticas e permanentes, pactuadas entre os entes da Federação e a sociedade [...]. (BRASIL, 2012)

Os Municípios que não aderiram ao SUAS na forma da NOB SUAS, aprovada pela Resolução no 130 , de 15 de julho de 2005, do Conselho Nacional de Assistência Social - CNAS, farão a adesão por meio da apresentação à Comissão Intergestores Bipartite - CIB de seu Estado dos documentos comprobatórios [...]. (CNAS, 2013, art. 10)

Em resumo, as experiências em desenvolvimento de Sistemas Nacionais (BRASIL, 2009; 2012) mostram que determinaçôes de competências constitucionais ou normas gerais, embora importantes, não foram suficientes para associar à implementação de políticas universais nas esferas locais proposiçóes de açóes mais "cooperativas", ou seja, que articulem relaçôes intergovernamentais. O desenho institucional das relaçóes intergovernamentais é, na atualidade, paulatinamente moldado em torno de mecanismos de monitoramento, regras flexíveis de gestáo mediante NOBs e assistência técnica e financeira do Executivo federal para a liberação dos recursos. São essas "novas" relaçôes intergovernamentais que o discurso político em torno do Sistema Nacional de Educação esta a configurar. Os governos subnacionais permanecem com uma função importante de aplicação dos recursos 
vinculados à $\mathrm{MDE}$, mas suas decisóes de alocação de gastos são afetadas pela regulamentação federal. As NOBs são variáveis importantes para a transferência de recursos e responsabilidades de implementação para os governos locais.

\section{Discursos em torno do SNE e relações intergovernamentais}

Este estudo operou a desconstrução analítica parcial do discurso, com o objetivo de, ao mesmo tempo, expressar-se sobre o terreno de seu interlocutor e contextualiza-lo. Desse modo, foi possível elaborar novas perguntas para investigaçóes qualitativas comparadas. A partir de 2007 a atribuição de regulação sistêmica dos serviços, que asseguram o direito à educação, flui para instâncias do Sistema Nacional, que congreguem setores representativos da sociedade, sob a coordenação do executivo federal. Atores com capacidade de vocalização em eventos da área e a literatura de política educacional convergem na defesa da regulamentação de um regime de colaboraçáo, mediante o discurso de articulação do Sistema Nacional de Educação no país. A experiência brasileira das últimas duas décadas revelou, também, que essas relaçóes contam com a interveniência de um Sistema de Monitoramento das açóes desenvolvidas pelos entes federados subnacionais, que recebem assistência técnica e financeira da União.

O discurso em torno do SNE é composto por um conjunto diverso de medidas de regulação das políticas públicas em educação, dentre eles a construção de diferentes espaços institucionais de participação. A disseminação desse discurso contribui, desse forma, para a formação do consentimento ativo dos atores sociais envolvidos em fóruns diversos para vocalização de suas demandas. Este estudo demonstrou que as funçóes políticas previstas para esses espaços são diversas e desiguais e aqueles com maior capacidade propositiva ou de regulamentação são compostos por representantes das diferentes instâncias governamentais. A análise de como interagem o executivo federal com os governos subnacionais expóe, ainda, as relaçóes entre os elementos centrais da construção discursiva em torno do SNE com dispositivos aparentemente no seu exterior, os mecanismos de financiamento mediante vinculação de recursos. Esses novos arranjos institucionais contribuíram para reduzir relações intergovernamentais competitivas predatórias entre os níveis de governo? Há efetivamente restrições postas à autonomia decisória e de alocação de gasto aos governos subnacionais? Como avaliar o impacto da regulação federal nas prioridades locais de gasto vis a vis os interesses dos grupos sociais com maior capacidade de organização e vocalização? Concluir um estudo com questôes já formuladas pela literatura da área tem por objetivo revelar a importância de aprofundar estudos comparados a respeito das políticas locais de administração dos sistemas educacionais.

Se a racionalidade legitimadora, que subjaz ao planejamento normativo aprovado no século XXI, orienta-se para a redução das disparidades de condiçôes 
presentes nas escolas brasileiras, reduçáo dos baixos salários pagos aos profissionais de educação e pela melhoria dos resultados médios de proficiência em língua portuguesa e matemática, o discurso em torno da construçáo de um Sistema Nacional de Educação, como meio para se atingir esses objetivos, permitiu aos grupos sociais no executivo federal estabelecer um princípio regulador das relaçóes intergovernamentais. A permanência de diferentes formas de desigualdades inter e intraregional, simultaneamente causa e produto do sistema federativo, requer, sob nosso ponto de vista, medidas de cunho redistributivo para sua superação ao longo do território da federação. O que se verifica, entretanto, é um desenho de políticas públicas em educação articuladas pela transferência direta de recursos técnicos e financeiros para os entes subnacionais, coordenadas pelo executivo federal, sob o manto da construção discursiva de um Sistema Nacional de Educação, que se cala a respeito de atribuiçóes redistributivas.

\section{Notas}

1. Este estudo insere-se em continuidade a Duarte e Santos (2014) e contou com o apoio de bolsa de estudos de doutorado sênior da Capes.

2. Sobre a noção de mecanismo ver: Dupuy (2012); Maggetti (2012).

3. Ao advogarmos por um Sistema Nacional de Educaçáo como o conceituamos? Dourado (2013) expóe a diversidade de acepçôes orientadoras dos significados atribuídos ao SNE e os desdobramentos de reforma sistêmica que passam a requerer. O conceito sintetizado por Saviani (1999) foi problematizado por Duarte (2011) a partir de pressupostos sócio interacionistas, ao considerar arranjos de planejamento educacional em desenvolvimento no país. Archer (2013) por sua vez conceitua sistema educacional como: "[...] uma coleção de âmbito nacional e diferenciada das instituiçôes dedicadas à educação formal, cujo controle e supervisão geral é, pelo menos em parte, governamental e cujos componentes e processos estão relacionados um ao outro." (ARCHER, 2013, p. 54) Neste caso, e consequente com ordem política federativa, o sistema estatal de educação no Brasil abrangeria a distribuição de atribuições aos entes da federaçâao na formação, manutençăo e regulamentação do desenvolvimento das instituiçôes públicas e privadas, a regulação dos modos de articulação e coordenação das açôes entre atores governamentais e não governamentais e o controle dos processos e resultados da formação ofertada ao longo do território.

4. Dentre esses citamos: Campanha Nacional pelo Direito à Educação; Confederação Nacional do Trabalhadores da Educação, União dos Dirigentes Municipais de Educação etc.

5. No período de tramitaçáo da PEC no 277 e seus apensados, os debates no Congresso Nacional versaram, prioritariamente, sobre o percentual desvinculado de receitas da Uniáo com o objetivo de ampliar os recursos destinados obrigatoriamente à educação.

6. Este evento congregou mais de 6.000 educadores brasileiros em Brasília em março de 2010, após processo de mobilização nos estados e nos municípios.

7. Sistema Único de Saúde (SUS), Sistema Nacional de Assistência Social (Suas), Sistema Nacional de Cultura (SNC) e Sistema Nacional de Educação (SNE)

\section{Referências}

ABREU, M. A. A. Educação: um novo patamar institucional. Novos Estudos - CEBRAP, São Paulo, n. 87, p. 131-143, 2010. 
ADRIÃO, T.; GARCIA, T. Oferta educativa e responsabilização no PDE: o Plano de Ações Articuladas. Cadernos de Pesquisa, São Paulo, v. 38, n. 135, p. 779-796, 2008.

ARAUJO, G. C. D. Constituição, federação e propostas para o novo Plano Nacional de Educação: análise das propostas de organização nacional da educação brasileira a partir do regime de colaboração. Educação \& Sociedade, Campinas, v. 31, n. 112, p. 749-768, 2010.

ARCHER, M. S. Social origins of educational systems. London: Roudledge, 2013.

ARRETCHE, M. Federalismo e igualdade territorial: uma contradição em termos? Dados, Rio de Janeiro, v. 53, n. 03, p. 587-620, 2010.

AVRITZER, L. Sociedade civil, instituiçôes participativas e representação: da autorização à legitimidade da ação. Dados, Rio de Janeiro, v. 50, n. 03, p. 443-464, 2007.

AZANHA, J. M. P. Política e planos de educação no Brasil: alguns pontos para reflexão. Cadernos de Pesquisa, São Paulo, n. 85, p. 70-78, 1993.

BEN-AYED, C. Entre universalisme et développement local: l'émergence d'une nouvelle école en France? Revue internationale d'éducation de Sèvres, Paris, n. 46, 2007.

. Le nouvel ordre éducatif local. Paris: Presses Univesitaries de France, 2009.

BEN-AYED, C. De l'école démocratique à l'école ségregative: la reforme de la carte scolaire. In: BEN-AYED, C. (Ed.). L école démocratique: vers un renoncement politique. Paris: Armand Colin, 2010.

BOWE, R.; BALL, S.; GOLD, A. Reforming education and changing schools: case studies in policy sociology. London: Routledge, 1992.

BRASIL/CONAE. Construindo o sistema nacional articulado de educação: o Plano Nacional de Educação, diretrizes e estratégias de ação. Documento final. Brasília: Ministério da Educação, 2010.

CALLON, M.; LASCOUMES, P.; BARTHE, Y. Acting in an uncertain world: an essay on technical democracy. London: MIT PRESS, 2009.

CAMARGO, R. B. D.; PINTO, J. M. D. R.; GUIMARÁES, J. L. Sobre o financiamento no Plano de Desenvolvimento da Educação. Cadernos de Pesquisa, São Paulo, v. 38, n. 135 , p. 817-839, 2008.

CHABROL, C. Réguler la construction de l'identité du sujet du discours. In: BERRENDONNER, A. e PARRET, H. (Ed.). L'interaction communicative. Bern, Frankfurt/M., New York, Paris: Peter Lang, 1990. 231p. [Sciences pour la communication].

CHARAUDEAU, P. Princípio de regulação. In: CHARAUDEAU, P.; MAINGUENEAU, D. (Ed.). Dicionáro de Análise do Discurso. São Paulo: Contexto, 2012.

CURY, C. R. J. A Educação Básica no Brasil. Educação \& Sociedade, Campinas, v. 23, n. 80, p. 168-200, 2002.

. Sistema nacional de educação: desafio para uma educação igualitária e federativa. Educação \& Sociedade, Campinas, v. 29, p. 1187-1209, 2008. 
CURY, C. R. J. Os desafios da construção de um Sistema Nacional de Educaçáo. In: QUEIROZ, A. C. D.; GOMES, L. (Ed.). Reflexōes sobre o Sistema Nacional Articulado de Educação e o Plano Nacional de Educação. Brasília, DF: Inep/MEC, 2009. 107p.

CURY, C. R. J. A questão federativa e a educação escolar. In: OLIVEIRA, R. P.; SANTANA, V. (Ed.). Educação e federalismo no Brasil: combater as desigualdades, garantir a diversidade. Brasília: Unesco, 2010, p.149-168.

DOURADO, L. F. Avaliação do Plano Nacional de Educação 2001-2009: questóes estruturais e conjunturais de uma política. Educação \& Sociedade, Campinas, v. 31, n. 112, p. $677-705,2010$.

. F. Sistema Nacional de Educação, Federalismo e os obstáculos ao direito à educação básica. Educação \& Sociedade, Campinas, v. 34, n. 124, p. 761-785, 2013.

DRAIBE, S. A nova institucionalidade do sistema brasileiro de políticas sociais: os conselhos nacionais de políticas sociais. Caderno de Pesquisa. Campinas: Núcleo de Estudos de Políticas Públicas/Unicamp,1998.

DUARTE, M. R. T. Sistema Eduacional no Brasil: articulação e diversidade. In: OLIVEIRA, D. A.; DUARTE, A. C. (Ed.). Políticas públicas e educação: regulação e conhecimento. Belo Horizonte: Fino Traço, 2011.

DUARTE, M. R. T.; JUNQUEIRA, D. S. A propagação de novos modos de regulação no sistema educacional brasileiro: o Plano de Açóes Articuladas e as relaçóes entre as escolas e a União. Pro-Posiçôes, Campinas, v. 24, n. 02, p. 165-193, 2013.

DUARTE, M. R. T.; OLIVEIRA, R. D. F. Sistemas municipais de ensino em Minas Gerais: o papel dos conselhos municipais de educação. Educação em Revista, Belo Horizonte, v. 28, n. 04, p. 243-262, 2012.

DUARTE, M. R. T.; SANTOS, M. R. S. Planejamento e participação: os eventos nacionais na área da educação após a Constituição de 1988. Educação, Porto Alegre, v. 37, n. 02, p. 167-179, 2014.

DUPUY, C. Ce que la comparaison qualitative de politiques infranationlales fait aux débats théoriques. Revue internationale de politique comparée, Paris, v. 19, n. 02, p. 121-140, 2012.

FAIRCLOUGH, N. Discurso e mudança social. Brasília: Editora UNB, 2001.

FERREIRA, N. S. C. Repensando e ressignificando a gestão democrática da educação na "cultura globalizada". Educação \& Sociedade, Campinas, v. 25, n. 89, p. 1227-1249, 2004.

FNDE, F. N. D. D. D. E. Apresentação do Plano de Açôes Articuladas (PAR). Brasília, DF: FNDE, 2014.

FOUCAULT, M. Segurança, território, população. São Paulo: Marttins Fontes, 2008. [Curso no College de France 1977-1978].

HORTA, J. S. B. Liberalismo, tecnocracia e planejamento educacional no Brasil: uma contribuição à história da educação brasileira no período de 1930-1970. São Paulo: Cortez; Autores associados, 1982. 226p. 
KRAWCZYK, N. R. O PDE: novo modo de regulação estatal? Cadernos de Pesquisa, São Paulo, v. 38, n. 135, p. 797-815, 2008.

LASCOUMES, P.; LE GALÈS, P. Sociologie de l'action publique. Paris: Armand Colin, 2007.

MAGGETTI, M. Le problème de l'interdépendance dans la comparaison des politiques publiques infranationales: une méta-analyse des mécanismses de diffusion. Revue internationale de politique comparée, Paris, v. 19, n. 02, p. 99-120.

MAROY, C. École, régulation et marché: une comparation de six espaces scolares locaux en Europe. Paris: Presse Universitaire de France, 2006.

MASSON, G. Implicaçóes do plano de desenvolvimento da educação para a formaçáo de professores. Ensaio: Avaliaçāo e Políticas Públicas em Educaçâo, Rio de Janeiro, v. 20, n. 74, p. 165-184, 2012.

OLIVEIRA, D. A. Das políticas de governo à política de estado: reflexóes sobre a atual agenda educacional Brasileira. Educação \& Sociedade, Campinas, v. 32, n. 115, p. 323337, 2011.

ROJAS BUVINICH, D. P. O mapeamento da institucionalização dos conselhos gestores de políticas públicas nos municípios brasileiros. Revista de Administração Pública, Rio de Janeiro, v. 48, n. 01, p. 55-82, 2014.

SAUER, A. H. Regime de Colaboração entre os Sistemas de Ensino. Parecer CNE/CP n. 11/2012. Brasília: MEC/CNE. Aprovado em 04.06.2012.

SAVIANI, D. A nova lei da educação: trajetória, limites e perspectivas. 2 ed. Campinas: Autores Associados, 1997.

. Sistemas de ensino e planos de educação: o âmbito dos municípios. Educação \& Sociedade, Campinas, v. 20, n. 69, p. 119-136, 1999.

. Desafios da construção de um sistema nacional articulado de educação. Trabalho, Educação e Saúde, Rio de Janeiro, v. 6, n. 02, p. 213-232, 2008.

SOUZA, Â. R. D. Explorando e construindo um conceito de gestão escolar democrática. Educação em Revista, Belo Horizonte, v. 25, n. 03, p. 123-140, 2009.

SOUZA, D. B.; CASTRO, D. F. Gestão democrática da educação sob perspectiva comparada Brasil-Portugal: entre a exigência legal e a exequibilidade real. Educação \& Sociedade, Campinas, v. 33, n. 121, p. 1195-1213, 2012.

VIANA, A. L. D. Á.; LIMA, L. D. D.; OLIVEIRA, R. G. D. Descentralização e federalismo: a política de saúde em novo contexto - liçóes do caso brasileiro. Ciência \& Saúde Coletiva, Rio de Janeiro, v. 7, n. 03, p. 493-507, 2002.

\section{Legislação consultada}

BRASIL. Manifesto dos Pioneiros da Educação Nova, 1932. Disponível em <http://www. histedbr.fe.unicamp.br/revista/edicoes/22e/doc1_22e.pdf>. 
BRASIL. Lei n. 4.024 de 20 de dezembro de 1961, fixa as Diretrizes e Bases da Educação. . Constituição da República Federativa do Brasil. Assembleia Nacional Constituinte. 1988 .

. Projeto de Lei n. 1.258, de 29 de novembro de 1988, que fixa as diretrizes e bases da educação nacional. 1988a. Disponível em <http://imagem.camara.gov.br/Imagem/d/ pdf/DCD29NOV1988.pdf\#page=9>. Acesso em 16.07.2014.

. Emenda Constitucional n. 14 de 12 de dezembro de 1996, que modifica os arts. 34, 208, 211 e 212 da Constituição Federal e dá nova redação ao art. 60 do Ato das Disposiçóes constitucionais Transitórias. 1996.

. Lei no 9394 de 20 dezembro de 1996, que estabelece as diretrizes e bases da educaçáo nacional. 1996a.

. Emenda Constitucional n. 53 de 19 de dezembro de 2006, que dá nova redação aos arts. 7o, 23, 30, 206, 208, 211 e 212 da Constituição Federal e ao art. 60 do Ato das Disposições Constitucionais Transitórias.

. Emenda Constitucional n. 59 de 11 de novembro de 2009, acrescenta $\$ 3^{\circ}$ ao art. 76 do Ato das Disposiçóes Constitucionais Transitórias para reduzir, anualmente, a partir do exercício de 2009, o percentual da Desvinculação das Receitas da União incidente sobre os recursos destinados à manutenção e desenvolvimento do ensino de que trata o art. 212 da Constituição Federal, dá nova redação aos incisos I e VII do art. 208, de forma a prever a obrigatoriedade do ensino de quatro a dezessete anos e ampliar a abrangência dos programas suplementares para todas as etapas da educação básica, e dá nova redação ao $\mathbb{\$}$ $4^{\circ}$ do art. 211 e ao $\$ 3^{\circ}$ do art. 212 e ao caput do art. 214, com a inserção neste dispositivo de inciso VI.

. Emenda Constitucional no 71 de 29 de novembro de 2012, acrescenta o art. 216-A à Constituição Federal para instituir o Sistema Nacional de Cultura.

. Lei no 13.005 de 25 de junho de 20014, que aprova o Plano Nacional de Educação - PNE e dá outras providências. Publicada no Diário Oficial da União, de 27 de junho de 2014 .

. Projeto de Lei Complementar no 413 de 22 de julho de 2014, que visa responder especificamente às disposiçôes do artigo 23 da Constituição Federal, acelerada, agora, pela recente sanção da Lei no 13.005/2014 que estabelece o Plano Nacional de Educação e dá outras providências. 2014a. Disponível em: <http://www.camara.gov.br/proposicoesWeb/ fichadetramitacao?idProposicao=620859>. Acesso em 15.10.2014.

CONSELHO NACIONAL DE ASSISTÊNCIA SOCIAL. Resolução n. 33 de 12 de dezembro de 2012, que aprova a Norma Operacional Básica do Sistema Único de Assistência Social.

Recebido em 10 de dezembro de 2014.

Aprovado em 27 de fevereiro de 2015. 